\title{
The number of moths caught by light traps is affected more by microhabitat than the type of UV lamp used in a grassland habitat
}

\author{
JULIA NIERMANN (D) and Gunnar BREHM D \\ Institut für Zoologie und Evolutionsforschung mit Phyletischem Museum, Friedrich-Schiller Universität Jena, Jena, Germany; \\ e-mails: julia_niermann@aol.de,gunnar.brehm@uni-jena.de
}

\begin{abstract}
Key words. Lepidoptera, insects, light-trapping, sampling method, traps, grassland, microhabitat, biodiversity monitoring, insect monitoring
\end{abstract}

\begin{abstract}
We compared the performance of three entomological LED lamps that differed in intensity and wavelength composition by using them to catch 2257 individuals of 161 species and 11 families of nocturnal Lepidoptera in two grassland habitats (dry grassland and orchard meadow). The study was carried out in June and July 2020 in the Jenzig conservation area (Jena, Germany, $\left.50^{\circ} 56^{\prime} 12^{\prime \prime} \mathrm{N}, 11^{\circ} 37^{\prime} 37^{\prime \prime} \mathrm{E}\right)$. In each habitat, we sampled three microhabitats that were either exposed, moderately sheltered or sheltered. Data were analysed using generalized linear mixed models. A lamp with high radiant flux (LepiLED maxi: $1.34 \mathrm{~W}$ mixed radiation) attracted $37 \%$ more moths and $5 \%$ more species than a lamp with a lower radiant flux (LepiLED mini: $0.55 \mathrm{~W}$ mixed radiation). The maxi lamp also attracted $17 \%$ more moths and $6 \%$ more species than the same lamp with UV radiation only (LepiLED maxi switch UV mode: $0.59 \mathrm{~W}$ ). However, the maxi lamp only performed significantly better in exposed microhabitats, whereas the UV lamp performed similarly in the sheltered and moderately sheltered sites. The number of individuals caught in the dry grassland habitat was greater than in the orchard meadow (1288 vs. 969), whereas the number of species was similar in both habitats (120 vs. 128). Higher numbers of individuals were caught in the moderately sheltered sites than in the sheltered and exposed sites (935 vs. 773 vs. 549 ). The same trend was seen in the number of species (119 vs. 113 vs. 110). The communities of moths caught by traps with different lamps were similar. We conclude that light-trapping is a robust method that delivers comparable results even when different lamps are used. The use of several weak lamps is more efficient and results in larger catches than the use of a single strong lamp.
\end{abstract}

\section{INTRODUCTION}

With the increasing attention on the global decline in biodiversity, moths have received more attention as indicator organisms (e.g. Wirooks, 2004; Rákosy \& Schmitt, 2011; Dar \& Jamal, 2021). While the monitoring of butterflies is established in many countries and on comparatively large scales (van Swaay et al., 2008; Richter et al., 2018), moths have so far received less attention in such schemes because they are taxonomically more challenging and far more species rich: The number of "macro moths" alone (a paraphyletic assemblage of traditionally collected larger moth clades) is approximately six times greater than the number of butterflies in Germany (Steiner et al., 2014). However, moths are considered to be good indicator organisms for habitat quality (Kitching et al., 2000), and indeed groups such as hawkmoths and geometrid moths are increasingly used as model organisms globally (e.g., Beck et al., 2017; Chiquetto-Machado et al., 2018; Enkhtur et al., 2021). Despite their more difficult taxonomy, moths provide at least two important advantages: As compared to diurnal butterflies, analyses of moth diversity are more likely to provide statistically significant results because of their higher spe- cies richness and their presence in habitats where relatively few butterfly species occur, such as dense forests in Central Europe (Dorow et al., 2019) or high elevation habitats in the Andes, where there is a declining richness in butterflies (Despland et al., 2012), but a high diversity of some moth taxa (e.g. Brehm et al., 2016). Secondly, light-trapping has proven an extremely efficient tool for sampling moths and other nocturnal insects (Montgomery et al., 2021), and it results in far larger numbers of individuals available for analysis than the search for caterpillars (Wirooks, 2006), bait catching (Niermann \& Brehm, 2019) or other methods.

Conventionally used lamps for light-trapping include mercury vapour lamps or fluorescent tubes, but LED lamps specifically designed for this purpose have become increasingly popular in the last few years. They are attractive to insects, small, lightweight and use little energy (Brehm, 2017; Infusino et al., 2017), allowing the use of lightweight lithium batteries in the field. Artificial light at night (ALAN) can have significantly negative effects on populations of insects (Owens et al., 2020), whose populations in Central Europe, for example, have been declining for years (Hallmann et al., 2017). Brehm et al. (2021) show 
that short-wave radiation (i.e. UV radiation and blue light) is particularly attractive, and thus potentially dangerous, for insects. Specifically developed UV LED lamps for the scientific collection of insects predominantly use precisely these wavelengths (Brehm, 2017). To our knowledge, however, no studies have compared lamps which differed in the quantity of their radiant flux, but are otherwise identical. Such lamps are already on the market for different applications: Many researchers want to use the most powerful lamp available to catch as many moths as possible in a short time, as reported by Brehm (2017). However, models with somewhat lower emissions consume significantly less energy, meaning that they can be operated for much longer periods of time using the same battery, for example in traps. Our comparison therefore includes such an energy-saving model (LepiLED mini) and a powerful model (LepiLED maxi). The latter can also be operated in pure UV mode without other radiation components (LepiLED maxi switch $U V$ mode, henceforth abbreviated as $U V$ ). Our investigation also includes the latter lamp. We selected two grassland habitats in the vicinity of Jena as a study area, and in each habitat we caught moths at sites that differed in exposure.

We tested the following hypotheses:

(1) A lamp with a high radiant flux (maxi) attracts more individuals and species than one with low radiant flux (mini), but we expect a non-linear relationship between these parameters according to the Weber-Fechner law.

(2) A $U V$ lamp attracts more individuals and species than one with similar emission in mixed mode (mini). Overall, we expect the ranking maxi $>U V>$ mini.

(3) A UV lamp attracts a similar spectrum of moths as a lamp with different wavelengths because moths behave overall similarly (see Brehm et al., 2021).

(4) We expected similar numbers of individuals and species richness in the two grassland habitats investigated, but more moths at exposed sites because of the wider effective radius of the lamps than in sheltered sites in the vicinity of bushes.

\section{MATERIAL AND METHODS}

\section{Sampling and identification}

We used three commercially available LepiLED lamps (Insects \& Light, Jena, Germany), based on the prototype developed by Brehm (2017). All are equipped with eight Nichia power LEDs, the emission maxima of which are in the areas of maximum sensitivity of the photoreceptors of various Lepidoptera and other insects (Briscoe \& Chittka, 2001). Four LEDs emit radiation in the UV range (peak at $365 \mathrm{~nm}$ ), two in the blue range (peak at $450 \mathrm{~nm}$ ) one in the green range (peak at $520 \mathrm{~nm}$ ), plus one cool white LED (Brehm et al., 2021). Radiant flux of mini was 0.55 $\mathrm{W}$, radiant flux of maxi was $1.34 \mathrm{~W}$, and radiant flux of $U V$ was $0.59 \mathrm{~W}$ (Fig. S1). In the latter lamp, only the four UV LEDs were switched on. Note that the UV lamp used by Brehm et al. (2021) had a lower radiant flux $(0.38 \mathrm{~W})$; otherwise the lamps used are identical.

The emission spectra of the lamps are shown in Fig. S2. Power bank batteries (EC-Technology, 22.4 Ah, $5 \mathrm{~V}$ ) provided electricity for each of the lamps. Lamps were attached to trees at a height of approximately $1.5 \mathrm{~m}$ (Fig. S3). Distances between the lamps ranged between $26.4 \mathrm{~m}$ and $46.9 \mathrm{~m}$. We expected no interaction between the lamps because the radius of attraction of any lamp decreases by the square of the distance and reaches usually less than 10-20 m (Truxa \& Fiedler, 2012). Moths were collected using funnel traps with three vanes made of extruded polypropylene (Insects \& Light, Jena, Germany). All lamps could thus be operated simultaneously. Trap design corresponded approximately to the design described by Brehm \& Axmacher (2006), using a cylindrical net (Fig. S3). We use the term "attracted" when comparing the performance between lamps and "caught" when dealing with specific numbers of individuals and species removed from each trap. We assume that relative percentages of attracted and captured moths are the same because the same type of trap was used for all lamps. The majority of the individuals caught were determined on site, their sex was noted and then released. One individual of each species as well as individuals that could not be determined on site were pinned, spread, labelled and deposited in the collection of the Phyletisches Museum Jena (PMJ); in total 384 individuals.

Identification was carried out using the illustrated field guide "Die Nachtfalter Deutschlands" ("Moths of Germany") (Steiner et al., 2014) and the reference collection in PMJ that includes individuals of all macro moth species recorded in the region over the last ca. 100 years. Dominant plants were identified using Jäger et al. (2017). Sampling started $30 \mathrm{~min}$ after sunset and was carried out for three hours per night between June and July 2020 during twelve nights around new moon (raw data provided in electronic supplementary material). Three lamps were used in the field work, one of each type, per night in one of the two habitats. After one night each lamp was placed at the next site within the same habitat. After three nights, they were moved to the second habitat and the same procedure repeated. This summed up to six nights in June 2020. Sampling was repeated in July 2020 in the same order to obtain two nightly samples for each lamp at every site.

\section{Study area}

This study was carried out at "Großer Gleisberg - Jenzig", which is part of the European Natura 2000 network and extends over 816 ha at elevations between 290 and $350 \mathrm{~m}$ (Köhler, 2000). Climate in this region is continental with annual precipitation around $600 \mathrm{~mm}$ (Heinker et al., 2017). Geology is tertiary, with red sandstone at the base of steep shell limestone areas including the plateaus with the $385 \mathrm{~m}$ Jenzig mountain (Heinker et al., 2017). We sampled in two adjacent habitats, both on southernexposed slopes: Habitat 1 (sites 1-3) was a semi-dry orchard meadow (with partially dead trees) at elevations between 245 and $261 \mathrm{~m}$ (Köhler et al., 2000) with modest steepness (Fig. S4a). Habitat 2 (sites 4-6) was characterized by very dry grassland on a steep slope with a high proportion of gravel and rubble along the lower border of a black pine stand at elevations between 373 and $382 \mathrm{~m}$ (Fig. S4b). In each habitat, one site was in an exposed position (distance to next bushes $>10 \mathrm{~m}$ ), in a moderately sheltered position (distance to next bushes $>2 \mathrm{~m}$ ) and in a sheltered position (close to bushes) in order to include a variety of microhabitats. A map is shown in Fig. S5 and geographic coordinates are provided in Table S1.

\section{Environmental data}

In both habitats, a USB data logger (Pro-USB 2, Lascar Electronics, UK) was installed at a height of $1 \mathrm{~m}$ close the most central site sampled (sites 2 and 5). According to the setting, the ambient temperature $\left({ }^{\circ} \mathrm{C}\right)$ and relative humidity $(\%)$ was recorded every minute. The data was read out using Easy Log USB software, version 7.6.0.0. For the evaluations, the arithmetic mean of the data was used, which was recorded during the operation of the traps in 
the respective habitats. The average percentage cloud cover was estimated for each of the three-hour nights. In the same way, the wind strength was estimated on a relative scale of $1-3$.

\section{Data analysis}

The statistical analyses and visualizations of the results were carried out in RStudio (Version 1.3.1073, RStudio, PBC, 20092020). The regression models created for the analysis of the number of species and individuals caught are mixed generalized linear models (GLMER) with a negative-binomial distribution of the residuals (GLMER.NB), which are created using the lme4 package [version 1.1-23 (Maechler et al., 2015)] and MASS [Version 7.3-53 (Venables \& Ripley, 2002)]. Each regression model was initially created as a maximum model considering all the weather parameters (humidity, temperature, wind and cloud cover) recorded and reduced by deleting the non-significant weather parameters in order to obtain the minimum adequate model. First, the number of individuals and the number of species that could be counted for the different lamps per recording was considered in two regression models (Tables S2 and S3): The lamps and the recorded weather data (relative humidity, temperature, cloudiness and wind) were considered as fixed effects. Habitat and location were added as random effects (nested design), as was the change in the experiment (crossed design). To determine significant differences between the two habitats, the same procedure was used and a regression model was created for the number of individuals and another model for the number of species: The habitats as well as wind and cloud cover were taken into account as a fixed effect. Temperature and humidity were viewed as properties of the respective habitat and were not included as separate variables. Lamp, test run and the interaction of habitat and location were considered as random effects. This procedure was repeated a third time in order to determine differences between the individual locations: two further regression models, one with the number of individuals and one with the number of species per survey as a dependent variable, were created (Table S4). As explanatory variables, the locations were grouped into three groups according to the characteristics of their small-scale environment, with one location from each habitat being assigned to a group. As for the regression models of the habitats, only wind and cloud cover were included as further fixed effects, with the lamps and the test run as random effects. In the case of significant differences between the characteristics of the explanatory variables considered (lamp type, habitat, exposure category), a multiple comparison of these characteristics was carried out using the Tukey HSD test. Based on the results of the previous analyses, a $\chi^{2}$ test was carried out to determine the relationship between the site and the lamp used, considering the number of individuals caught. Finally, due to the small sample size, which was available for the investigation of the percentages of the sexes caught by the various lamps, the $\chi^{2}$ test was used to determine differences. The percentages of the sexes of all individuals and separately for the three most common families (Noctuidae, Geometridae and Erebidae) were compared in each case. Community analyses were conducted in $\mathrm{R}$ using the packages Vegan (Oksanen et al., 2020), Adespatial (Dray et al., 2021) and Ade4 (Dray et al., 2007). We calculated species richness, Shannon and Simpson diversity. Beta diversity was determined using the method of Baselga et al. (2010), which partitions nestedness and turnover. All single samples were ordinated using NMDS. A multi-level pattern analysis with 999 random permutations was conducted to evaluate indicator species for the different types of lamps. Results were visualized using the R packages GGplot2 (Wickham, 2016), Effects (Fox \&Weisberg, 2018), Ggeffects (Lüdecke, 2018), Ggpubr (Kassambara, 2020),
Dplyr (Wickham et al., 2021) and VennDiagram (Chen, 2018), and modified using Adobe Illustrator CS6 software.

\section{RESULTS}

A total of 2257 individuals of 161 species and 11 families were caught. The families with most individuals were Noctuidae (1265 individuals), Geometridae (510 individuals) and Erebidae (396 individuals). The five most abundant species were Noctua fimbriata (Noctuidae, 216 individuals), Eilema lurideola (Erebidae, 182 individuals), Eilema complana (Erebidae, 149 individuals), Idaea fuscovenosa (Geometridae, 120 individuals) and Noctua pronuba (Noctuidae, 115 individuals). Sex was determined for 1467 individuals, resulting in a total of 685 females and 782 males in the second part of the experiment (July 2020) and we do not expect any bias. A complete list of individuals, species and the data sampled is provided as raw data in the Electronic supplementary material $\mathrm{S} 2$.

The mean number of individuals caught was highest for maxi (sum 874) followed by $U V$ (sum 745) and mini (sum 638) (Fig. 1a). Detailed results are provided in Table S5. When numbers caught were compared between lamps, the difference between maxi and mini was significant (Tukey: $Z_{(2.27)}=-3.75, \mathrm{p}<0.001$, Table S6). The number caught by $U V$ was significantly lower than that by maxi (Tukey: $\mathrm{Z}_{(2.27)}$ $=-2.45, \mathrm{p}<0.05$, Table S6). There was no significant difference between $U V$ and mini catches (Table S6).

Species numbers showed a similar pattern, but overall differences were low. The total number of species caught was highest for maxi (sum 118) followed by mini (sum
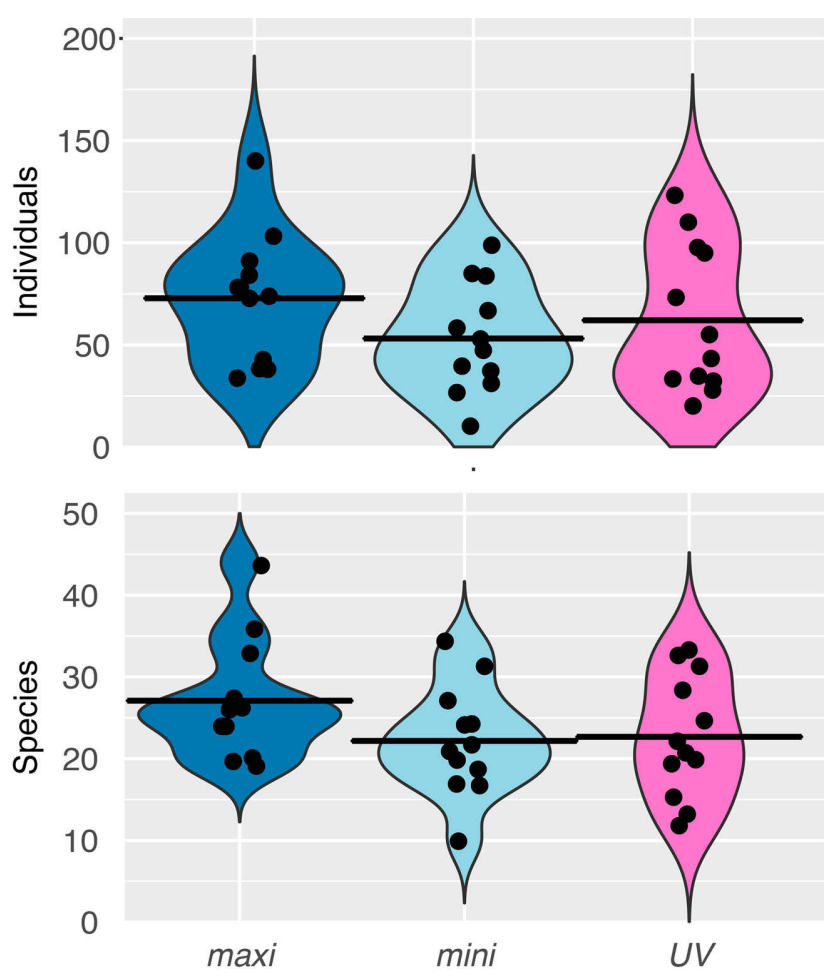

Fig. 1. a - numbers of individuals caught per night by traps with each of the three lamps (maxi, mini, maxi switch UV mode); b numbers of species caught per night. Mean values are represented by black bars. Black dots are nightly catches. 

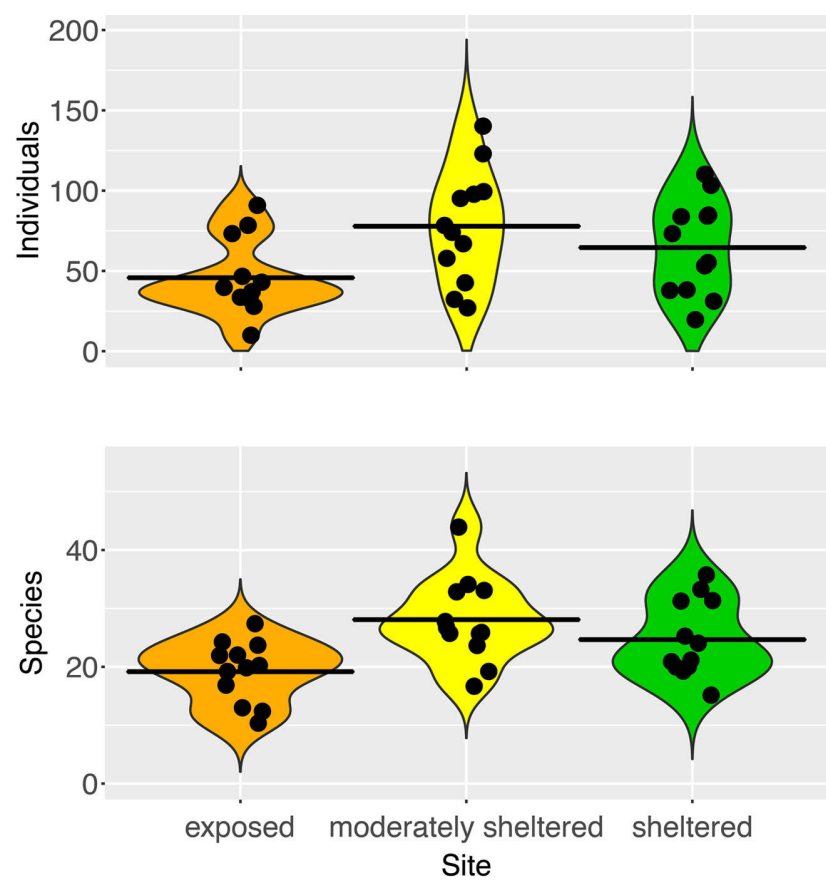

Fig. 2. a - number of individuals caught per night in three microhabitats. The black bars are mean values. $b-$ number of species caught per night. Black dots are nightly catches.

112) and $U V$ (sum 111) (Fig. 1b, Table S5). Only the difference between maxi and mini was significant (Tukey: $\mathrm{Z}_{(2.28)}$ $=-2.49, \mathrm{p}<0.05$, Table S6).

\section{Sex ratios}

A slightly higher (but not significantly different) percentage of males $(53.3 \%)$ was recorded across all taxonomic groups. Similar values were obtained for maxi $(54.3 \%)$, mini $(52.2 \%)$ and $U V(53.0 \%)$. There were no significant differences in the sex ratios recorded for the different lamps (Table S7). When considering the three most common families no differences in the sex ratios between lamps were recorded (Table S7).

\section{Comparison of habitats}

A higher mean number of individuals were caught in habitat 2 (mean 71.6, total 1288) than habitat 1 (mean 53.4 , total 969 , Table S8), but the differences were not significant. Further fixed effects were determined using the regression model, taking wind and cloud into account, but no significant difference was found $[\mathrm{Z}(1.28)=0.60, \mathrm{p}=$ 0.55 , see Table S3]. There were no significant differences in terms of the number of species (Table S3). Species abundance curves for both habitats were very similar (Fig. S6). Despite the closeness of the habitats, only two of the five commonest species were among the top five species caught (Table S9).

\section{Exposure of sites}

The differences in the number of individuals caught per lamp and detection are explained using a regression model that summarizes the locations of the sites according to their small-scale environment. The most exposed sites in both habitats (sites 1 and 4), the moderately sheltered sites

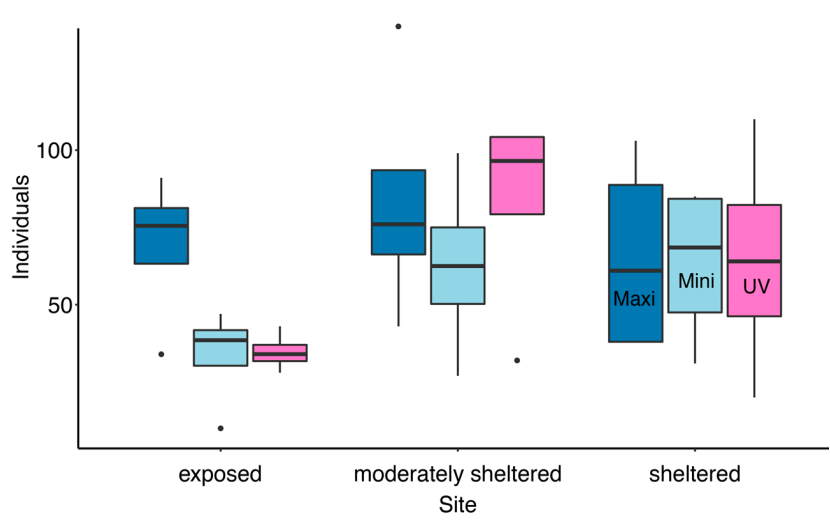

Fig. 3. Number of individuals caught per night by traps with three different lamps in three microhabitats.

near large vegetative structures (sites 3 and 5) as well as the sheltered sites close to dense vegetation (sites 2 and 6) were combined. Fig. 2 a shows the number of individuals caught per night and lamp in the three site categories and Fig. $2 b$ shows the same for species. The fewest individuals were caught at the exposed sites $(\mathrm{M}=45.8, \mathrm{SD}=23.2$, Table S10) and was highly significantly different [Z (2.27) $=4.83, \mathrm{p}<0.001$, Table S11] from that caught at the moderately sheltered sites $(\mathrm{M}=77.9, \mathrm{SD}=35.0$, Table $\mathrm{S} 10)$. Another significant but smaller difference $[Z(2.27)=0.34$, $\mathrm{p}=0.010$, Table S11] was recorded between the exposed and sheltered sites $(\mathrm{M}=64.4, \mathrm{SD}=29.6$, Table $\mathrm{S} 10)$. The moderately sheltered sites did not differ significantly from the sheltered sites $[\mathrm{Z}(2.27)=1.95, \mathrm{p}=0.126$, Table $\mathrm{S} 11]$.

The same trend was also found for species: The lowest numbers were caught at the exposed sites $(\mathrm{M}=19.2, \mathrm{SD}=$ 5.3, Table S10) and differed significantly $[Z(2.27)=2.97$, $\mathrm{p}=0.008$, Table S11] from the catches at the sheltered and moderately sheltered sites $[Z(2.27)=2.97, p=0.001$ Table $\mathrm{S} 11]$. The catches at sheltered locations $(\mathrm{M}=24.7, \mathrm{SD}=$ 6.6, Table S10) did not differ significantly $[\mathrm{Z}(2.27)=1.63$, $\mathrm{p}=0.126$ Table $\mathrm{S} 11]$ from that at the moderately sheltered locations $(\mathrm{M}=28.1, \mathrm{SD}=7.2$, Table $\mathrm{S} 10)$.

There was a highly significant relationship between the number of individuals, the type of lamp and exposure category [Fig. $\left.3 ; \chi^{2}(4)=49.23, p<0.001\right]$. At exposed locations, $50.3 \%$ of all individuals were caught with traps with maxi lamps while $U V$ and mini caught similar numbers. At moderately sheltered locations, maxi and $U V$ traps caught $35.8 \%$ and $37.7 \%$, respectively, whereas mini was the least attractive. At sheltered sites, on the other hand, similar percentages of individuals were caught by traps with all of the different types of lamps (Fig. 3, Table S12).

\section{Community analysis}

An NMDS ordination of 18 samples (6 sites * 3 lamps) shows a clear separation of the two habitats along the first axis (Fig. 4). Along the second axis, exposed sites tend to be separated from sheltered and moderately sheltered sites, whereas the two latter categories are intermingled. A Venn diagram shows a high total species overlap between all lamps with a slightly higher overlap between maxi and mini lamps as compared to maxi vs $U V$ and mini vs $U V$ 


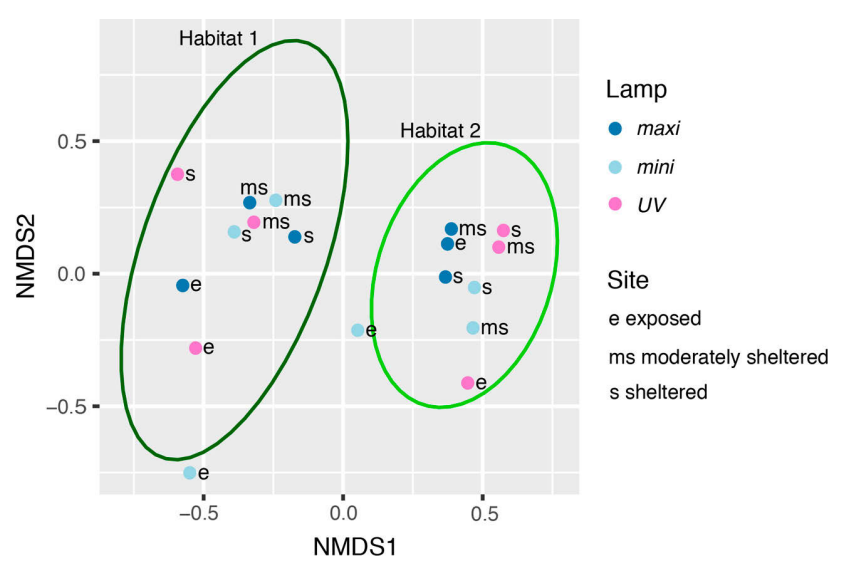

Fig. 4. NMDS ordination of 18 samples, each pooling the catches on two nights at the same site with the same lamp.

(Fig. S7). Beta diversity between all lamps was similar and values ranged between 0.17 and 0.21 (Fig. S8). The turnover partition was higher in comparisons that included the $U V$ lamp. Only a single indicator species was recorded, viz. Hyles euphorbiae as an indicator for the maxi lamp, with a total of six records for maxi, one for mini lamp and one for the $U V$ lamp.

\section{DISCUSSION}

Our study includes only a relatively small number of samples collected over a short period during the peak season of the year, but a considerable number of individuals and species, and clear and well interpretable patterns. The results confirm the expectation that a lamp with low radiant flux (mini) attracts fewer individuals and species than one with a high radiant flux (maxi). This was already reported by Brehm et al. (2021) with nearly the same set of lamps in an experiment under controlled conditions. A high attraction of lamps with high radiant flux was also reported e.g. by Justice \& Justice (2021) and Wakefield et al. (2016). The design of the choice experiment carried out by Brehm et al. (2021) had a competitive character with relatively close distances between the lamps $(10 \mathrm{~m})$ whereas this was not the case in our field experiment. While the radiant flux of the maxi lamp was $144 \%$ higher than that of the mini lamp, the number of individuals caught was on average only $37 \%$ higher and the number of species was only $5 \%$ higher. This confirms our expectation of a non-linear relationship between radiant flux and the number of individuals and species caught. Linear increases in radiation is perceived log-transformed by an insect eye according to the Weber-Fechner law (Brehm et al., 2021), but results under field conditions are also influenced by other factors, such as, microhabitat (see below). From a lamp user / field entomologist's perspective, it is important to consider the power consumption of the maxi lamp, which is more than three times that of a mini lamp because the radiant flux of the LEDs does not increase linearly with power consumption. This means there is a trade-off: optimizing for high efficiency favours small lamps such as mini, as three of them require about the same energy as one maxi lamp, but will attract many more individuals. Based on the results of this study, 874 individuals were caught by one trap with a maxi lamp, but theoretically ca. $3 * 638=1914$ individuals could be caught by three traps with mini lamps, with a similar total power consumption. This shows that a single large lamp performs worse than several small ones, which is the SLOSS debate in conservation ecology revisited in a different context. It must be acknowledged, however, that a single lamp requires a far lower investment by the user and is easier to carry in the field along with batteries and trap equipment.

As expected from indoor experiments (Brehm et al., 2021), the trap with the $U V$ lamp caught on average a higher number $(16 \%)$ of individuals than the trap with the mini lamp. This confirms the expectation of a higher efficiency of short waved radiation, because the radiant flux of both models was very similar. However, the difference is not statistically significant, and the exposure of a site plays an important role (see below). The total numbers of species caught by traps with $U V$ and mini lamps were practically identical.

The species composition of the catches of traps with all lamps was very similar, but the $U V$ lamp tended to attract a marginally different moth community, as illustrated by the Venn diagram, and there was a higher turnover partition of beta diversity in the catches of the trap with the $U V$ lamp. Hyles euphorbiae was the only species that was attracted significantly more by the maxi than the other lamps in this study. As it was only a single species and the total number was only seven individuals, however, it is not possible to conclude that $H$. euphorbiae will not be attracted by a $U V$ lamp. Many Sphingidae were caught by the $U V$ lamp in the indoor experiment of Brehm et al. (2021).

Importantly, lamps performed rather differently in different microhabitats: Maxi performed much better only at the exposed sites and was about as good as the other lamps in moderately sheltered and sheltered sites. We explain this by the potentially lower effective radius of a strong lamp in more sheltered sites; a strong lamp only has an advantage over a weak lamp if the effective radius of attraction is larger, and this is clearly the case in most open habitats. It is well known that short wave radiation is far more scattered by the atmosphere and dust than long wave radiation (Platt et al., 2007). However, we do not know whether this could also play a role at such small spatial scales of only a few meters. The effect, if present, could potentially explain why the $U V$ lamp performed less well at the exposed sites than the mixed radiation maxi lamp.

The two habitats differed only slightly with regard to abundance and species richness. We found a surprisingly strong effect of the exposure of the sites on the number of individuals and species. The highest total numbers were caught at the moderately sheltered sites, followed by the sheltered and exposed sites. However, numbers of individuals caught were also dependent on the type of lamp used (see above). Currently it is only possible to speculate about the reasons for the observed patterns, but moths may 
tend to avoid very exposed sites because the wind speed is higher there, which results in cooler temperatures, fewer flowers and little or no scent of potential mates, and possibly higher exposure to predators such as bats. On the other hand, the lamps at the most sheltered sites attracted fewer individuals because the effective radius of attraction is lowered by visual obstacles (bushes, trees) and possibly a lower availability of herbaceous hostplants. Moderately sheltered sites could thus be the "best of both worlds" and host the highest numbers. It is a generally observed that a high diversity of moths is associated with areas with many microhabitats (Bates et al., 2014). Moderately sheltered sites could also be important flight routes for moths, which often move along vegetation structures (Coulthard et al., 2016).

The 161 species of macro moths collected within a few weeks in 2020 clearly indicate that light-trapping is an unrivalled method for studying a moth fauna. As any other method, however, light-trapping misses some species and does not provide a fully representative sample of a moth community (Schönborn, 2003). Most of the moths present will not be caught, as is shown by Brehm et al. (2021) with a maximum of $18 \%$ and by Truxa \& Fiedler (2012) with a maximum of $25.5 \%$ sampled of those actually present. Some individuals will be attracted but are not caught because they only show up for a very short period or do not fall through the funnel. Our data also indicates a slight sampling bias for males over females that was already reported e.g. by Altermatt et al. (2009), Truxa \& Fiedler (2012) and Brehm et al. (2021). For a more complete survey of species, a longer sampling period and a combination of light-trapping, searching for pre-imaginal stages (Wirooks, 2006), observation of nectar sources (Wirooks, 2004) and bait catching (Niermann \& Brehm, 2019) would be required. Major advantages of using automatic light traps are standardization and the sampling of a certain number (but not an infinite number) of multiple microhabitats simultaneously (including also understorey-canopy comparisons), which rarely can be achieved using manual sampling methods.

Our data indicate that the protected area "Großer Gleisberg-Jenzig" is a species rich habitat and that there are a number of species on the German Red List of endangered species and the FFH Appendix II. Many taxa are dependent on base-rich open areas with sparse vegetation, but ongoing succession and increasing coverage with bushes threaten this type of habitat. A detailed analysis of the species composition of moths present is beyond the scope of this paper and will be published elsewhere.

In conclusion, our results show that light-trapping results in similar catches, independent of whether strong or weak lamps were used, or whether mixed radiation and UV lamps were used. Light trapping is therefore a robust method that delivers comparable results even when methodology between studies differs. Our data indicate that the choice of the site sampled in a habitat can have a significant influence on the number of individuals caught and (thus) species. We therefore recommend sampling at several sites in a habitat in order to catch most of the species present.
If sampling is constrained to one location in a habitat, we recommend moderately sheltered sites as potentially the most suitable in open and semi-open areas and encourage similar comparisons in other habitats and regions.

ACKNOWLEDGEMENTS. We thank D. Veit (Jena) for providing data loggers and help with the construction of traps, the Untere Naturschutzbehörde Jena / F. Hünefeld for issuing the required research permits, S. Halle for co-supervision of J.N's bachelor thesis as well as A. and J. Niermann for logistic support. Insects \& Light (Jena) provided lamps and traps for the experiments. We thank an anonymous reviewer and the editor for helpful and constructive comments.

\section{REFERENCES}

Altermatt F., Baumeyer A. \& Ebert D. 2009: Experimental evidence for male biased flight-to-light behavior in two moth species. - Entomol. Exp. Appl. 130: 259-265.

Baselga A. 2010: Partitioning the turnover and nestedness components of beta diversity. - Glob. Ecol. Biogeogr. 19: 134143.

Bates A.J., Sadler J.P., Grundy D., Lowe N., Davis G., Baker D., Bridge M., Freestone R., Gardner D., Gibson C. et al. 2014: Garden and landscape-scale correlates of moths of differing conservation status: significant effects of urbanization and habitat diversity. — PLOS ONE 9: e86925, 11 pp.

Beck J., McCain C.M., Axmacher J.C., Ashton L., Bärtschi F., Brehm G., Cizek O., Colwell R.K., Fiedler K., Francois C.L. ET AL. 2017: Elevational species richness gradients in a hyperdiverse insect taxon: a global meta-study on geometrid moths. - Glob. Ecol. Biogeogr. 26: 412-424.

BREHM G. 2017: A new LED lamp for the collection of nocturnal Lepidoptera and a spectral comparison of light-trapping lamps. - Nota Lepidopterol. 40: 87-108.

BREHM G. \& AXMACHER J.C. 2006: A comparison of manual and automatic moth sampling methods (Lepidoptera: Arctiidae, Geometridae) in a rain forest in Costa Rica. - Environ. Entomol. 35: 757-764.

Brehm G., Hebert P.D.N., Colwell R.K., Adams M.O., Bodner F., Friedemann K., Möckel L. \& Fiedler K. 2016: Turning up the heat at a hotspot: DNA barcodes reveal $80 \%$ more species of geometrid moths along an Andean elevational gradient. PLOS ONE 11: e0150327, 15 pp.

Brehm G., Niermann J., Jaimes Nino L.M., Enseling D., Jüstel T. \& FIEDLER K. 2021: Moths are strongly attracted to ultraviolet and blue radiation. - Insect Conserv. Divers. 14: 188-198.

BRISCOE D.B. \& ChITTKA L. 2001: The evolution of color vision in insects. - Annu. Rev. Entomol. 46: 471-510.

Chiquetto-Machado P.I., Amorim F.W. \& Duarte M. 2018: Long-term stability of the hawkmoth fauna (Lepidoptera, Sphingidae) in a protected area of Brazilian Atlantic rain forest. J. Insect Conserv. 22: 277-286.

Coulthard E., McCollin D. \& Littlemore J. 2016: The use of hedgerows as flight paths by moths in intensive farmland landscapes. - J. Insect Conserv. 20: 345-350.

DAR A.A. \& JAMAL K. 2021: Moths as ecological indicators: a review. - Munis Entomol. Zool. J. 16: 830-836.

Despland E., Humire R. \& San Martín S. 2012: Species richness and phenology of butterflies along an altitude gradient in the desert of northern Chile. - Arctic, Antarctic, Alpine Res. 44: 423-431.

Dorow W.H.O., Blick T., Pauls S.U. \& Schneider A. 2019: Forest Affinity of Selected Animal Groups in Germany. BfN 
Skripten 544, Bundesamt für Naturschutz, Bonn, 359 pp. [in German].

Ebert G., Bartsch D., Bettag E., Bläsius R., Blum E., Kallies A., SpatenKa K., Weber F., Ratzel U., Ratzel M. et al. 1997: The Butterflies of Baden-Württemberg. Vol. 5, Moths III. 5th ed. Ulmer, Stuttgart, 575 pp. [in German].

Enkhtur K., Brehm G., Boldgiv B. \& Pfeiffer M. 2021: Alpha and beta diversity patterns of macro-moths reveal a breakpoint along a latitudinal gradient in Mongolia. - Sci. Rep. 11: 15018,13 pp.

Fox J. \& Weisberg S. 2018: Visualizing fit and lack of fit in complex regression models with predictor effect plots and partial residuals. - J. Stat. Softw. 87: 9, 27 pp.

Hallmann C.A., Sorg M., Jongejans E., Siepel H., Hofland N., Schwan H., Stenmans W., Müller A., Sumser H., Hörren T., ET AL. 2017: More than 75 percent decline over 27 years in total flying insect biomass in sheltered areas. - PLOS ONE 12: e0185809, $21 \mathrm{pp}$

Heinker S., Heyn C. \& Schuster K. 2017: Management Plan (Technical Article Open Land) for the FFH Area 125 "Großer Gleisberg - Jenzig” (DE 5035-303). Technical report, Triops - Ökologie \& Landschaftsplanung GmbH, Halle (Saale), 201 pp. [in German].

Infusino M., Brehm G., Di Marco C. \& Scalercio S. 2017: Assessing the efficiency of UV LEDs as light sources for sampling the diversity of macro-moths (Lepidoptera). - Eur. $J$. Entomol. 114: 25-33.

Justice M.J. \& Justice T.C. 2021: Insect attraction to the six major types of traditional-style, residential light bulbs and implications for insect survival and light pollution. - bioRxiv PPR337249.

Kitching R.L., OrR A.G., Thalib L., Mitchell H., Hopkins M.S \& Graham A.W. 2000: Moth assemblages as indicators of environmental quality in remnants of upland Australian rain forest. - J. Appl. Ecol. 37: 284-297.

KöHLER G. \& Wagner G. 2000: Habitats of the red-winged wasteland insect, Oedipoda germanica (Latr.), and their association with other grasshopper species in Thuringia. - Mauritiana 17: 389-416 [in German].

LeINONEN R., Söderman G., ItÄmies J., RytKÖNEn S. \& RutANEN I. 1998: View of intercalibration of different light-traps and bulbs used in moth monitoring in northern Europe. - Entomol. Fenn. 9: 37-51.

LÜDECKE D. 2018: ggeffects: Tidy data frames of marginal effects from regression models. - J. Open Source Softw. 3: 772, 5 pp.

Maechler M., Bolker B. \& Walker S. 2015: Fitting linear mixed-effects models using lme4. - J. Stat. Softw. 67: 1-48.

Montgomery G.A., Belitz M.W., Guralnick R.P. \& Tingley M.W. 2021: Standards and best practices for monitoring and benchmarking insects. - Front. Ecol. Evol. 8: 579193, 18 pp.

NiermanN J. \& BReHM G. 2019: Biennial recording of nocturnal macromoths at baits on a fragment of alluvial forest at the Saale in Jena. - Mitt. Thüring. Entomologenverb. 26: 54-63 [in German].
Owens A.C.S., Cochard P., Durrant J., Farnworth B., Perkin E.K. \& Seymoure B. 2020: Light pollution is a driver of insect declines. - Biol. Conserv. 241: 108259, 9 pp.

Platt U., Pfeilsticker K. \& Vollmer M. 2007: Radiation and optics in the atmosphere. In Träger F. (ed.): Springer Handbook of Lasers and Optics. Springer, New York, NY, pp. 1165-1202.

POMPE S. 2004: Succession in abandoned vineyards in the Middle Saale Valley near Jena. - Hercynia 37: 175-199 [in German].

RÁkosy L. \& Schмiтt T. 2011: Are butterflies and moths suitable ecological indicator systems for restoration measures of seminatural calcareous grassland habitats? - Ecol. Indicat. 11: $1040-1045$.

Richter A., Hauck J., Feldmann R., Kühn E., Harpke A., Hirneisen N., Mahla A., Settele J. \& Bonn A. 2018: The social fabric of citizen science - drivers for long-term engagement in the German butterfly monitoring scheme. - J. Insect Conserv. 22: 731-743.

JäGER E.J. (ED.) 2017: Rothmaler - Excursion Flora of Germany. Springer, Heidelberg, $x+924$ pp. [in German].

SCHÖNBORN C. 2003: Methods of recording night butterflies - basics, possibilities and requirements for meaningful results. Beitr. Bayer. Entomofaun. 5: 7-15 [in German].

Steiner A., Ratzel U., Top-Jensen M. \& Fibiger M. 2014: The Moths of Germany - A Field Guide. BugBook Publishing, Østermarie, $878 \mathrm{pp}$.

Truxa C. \& Fiedler K. 2012: Attraction to light - from how far do moths (Lepidoptera) return to weak artificial sources of light? - Eur. J. Entomol. 109: 77-84.

Van Swahy C., Nowicki P., Settele J. \& Van Strien A.J. 2008: Butterfly monitoring in Europe: Methods, applications and perspectives. - Biodiv. Conserv. 17: 3455-3469.

Venables W.N. \& Ripley B.D. 2002: Package 'MASS.' Modern Applied Statistics with S. 4th ed. Springer, New York, xi +495 pp.

Wakefield A., Broyles M., Stone E.L., Jones G. \& Harris S. 2016: Experimentally comparing the attractiveness of domestic lights to insects: Do LEDs attract fewer insects than conventional light types? - Ecol. Evol. 6: 8028- 8036.

Wickham H., Navarro D. \& Pedersen T.L. 2016: Elegant Graphics for Data Analysis. Springer, New York, 276 pp.

Wirooks L. 2005: Possibilities and Limits of Light Capture in the Ecological Evaluation of Moth Species Spectra - A Comparison between the Spatial Distribution of Moth Imagines and that of Their Pre-imaginal Stages. PhD Thesis, RheinischWestfälische Technische Hochschule, Aachen, vi +265 pp. [in German].

Wirooks L. 2006: Area of light-trapping species spectra (Lepidoptera, Macroheterocera). - Mitt. Dt. Ges. Allgem. Angew. Entomol. 15: 403-408 [in German].

Received November 4, 2021; revised and accepted December 15, 2021 Published online January 14, 2022

Online supplementary files:

S1 (http://www.eje.cz/2022/004/S01.pdf). Figs S1-S8 and Tables S1-S12.

S2 (http://www.eje.cz/2022/004/S02.xlsx). Raw data: List of individuals, Site sampling data, Species site matrix. 